\title{
NOTAS SOBRE A RELAÇÃO ENTRE TRABALHO, EDUCAÇÃO PROFISSIONAL E FORMAÇÃ̃O EM NÍVEL MÉDIO PARA A DOCÊNCIA
}

\author{
Vera Lúcia Martiniak \\ Universidade Estadual de Ponta Grossa - UEPG \\ vemarti@bol.com.br \\ Renata de Almeida Vieira \\ Universidade Estadual de Maringá - UEM \\ realvieira@gmail.com
}

\section{RESUMO}

Este artigo $^{1}$ tem como objeto de estudo a formação de professores oferecida em nível Médio. Procura-se, pautado na categoria trabalho, explicitar o processo de esvaziamento da formação inicial de docentes, o qual colabora para uma acentuada desqualificação intelectual do professor. Aborda-se, para isso, o histórico da Educação Profissional e da Formação de Professores no Brasil. Apresentam-se, ainda, as concepções orientadoras da Educação Profissional no Estado do Paraná, com ênfase na Proposta Pedagógica Curricular do Curso de Formação de Docentes em nível Médio. Nesta Proposta, detecta-se uma fundamentação de tradição marxista baseada no trabalho como princípio educativo, concepção defendida como uma proposta alternativa de educação profissional, o que significa adotar como princípio metodológico a articulação dialética entre teoria e prática na perspectiva da práxis. Observa-se que, embora, no âmbito desta Proposta, tais categorias fazem-se presentes, ao confrontar suas proposições com a realidade vivenciada nos cursos de Formação de Docentes, tem-se como principal resultado a prevalência de uma concepção pragmática de formação. Diante do constatado, conclui-se que a grande distância entre o proposto e o efetivado tem suas raízes plantadas no terreno contraditório e antagônico das determinações do capital, cuja margem para consecução de propostas educativas alternativas que lhe são concorrentes e, até mesmo, negadoras, é, por demais, estreita.

Palavras-chave: Trabalho; Educação Profissional; Formação Docente.

\section{REMARKS ON THE TEACHER TRAINING IN HIGH SCHOOL WITH REGARDS TO WORK}

\begin{abstract}
This article aims to study the teacher training offered in high school. From the work point of view, we try to explain the decreasing demand process from the initial teacher education which contributes to a strong intellectual disqualification of the teacher. Therefore the history of Professional Education and teacher training in Brazil is addressed. We also present the guiding conceptions of the Professional Education in the state of Paraná with emphasis on those that rule the Curriculum Proposal of the Teacher Training Course. In such Proposal it is possible to note a Marxist foundation based on the work as an alternative proposal of professional education which means to adopt the dialectic articulation between theory and practice as a methodological principle in the praxis perspective. It is possible to observe that if these categories are present within the Proposal, by confronting their propositions with reality experienced in courses of Teacher Training the main result is the prevalence of a pragmatic conception of training. Based on the findings, it is possible to conclude that the distance between what is proposed and what is
\end{abstract}


put into effect has its roots based on the contradictory and antagonist determinations of money, whose scope for achievement of alternative educational proposals that are concurrent and even neglecting is really narrow.

Keywords: Work and Education; Professional Education; Teacher Training.

\section{Introdução}

As políticas educacionais brasileiras direcionadas à formação para a docência têm refletido os reajustes da sociedade atual e as implicações nas relações de trabalho. No contexto de reestruturação da produção capitalista, torna-se perceptível a situação em que se encontra a profissionalização docente, sobretudo quando se trata da sua formação inicial, marcada pelo esvaziamento de conhecimentos e desvalorização da profissão.

No texto que ora segue, fruto de pesquisa acerca da Educação Profissional e formação inicial de professores, indaga-se se haveria, no interior desse contexto, condições reais para consecução de propostas educativas alternativas a essa lógica dominante de formação do trabalhador em educação. Tal questionamento origina-se do estudo da Proposta Pedagógica Curricular para o curso de Formação de Docentes para a Educação Infantil e Anos Iniciais do Ensino Fundamental (PARANÁ, 2006), adotada nos cursos profissionalizantes em nível Médio para a docência no Estado do Paraná. Trata-se de um projeto pedagógico que se propõe alternativo à lógica hegemônica de formação de docentes, já que adota o trabalho como princípio educativo como um de seus princípios norteadores, propondo uma educação profissional que busque contrapor-se à desvalorização e aligeiramento da formação e do trabalho docente.

Intenciona-se, neste artigo, questionar sobre a possibilidade de se oferecer, concretamente, um curso de formação profissional orientado por uma perspectiva crítica em meio aos ditames da sociedade do capital. Para tanto, busca-se evidenciar o significado histórico da categoria trabalho em especial sob a forma capitalista, da educação profissional, bem como da formação para o magistério. Pretende-se, com isso, abordar as transformações ocorridas na Educação Profissional e formação de professores em nível médio, numa perspectiva histórica, de modo a evidenciar as configurações que esta modalidade de educação assume diante das exigências do mundo do trabalho e de formação do trabalhador.

\section{Notas sobre a categoria trabalho}

Um dos princípios pedagógicos que servem de referência aos pressupostos teóricometodológicos da organização curricular do Curso de Formação de Docentes para a Educação Infantil e Anos Iniciais do Ensino Fundamental, na modalidade Normal, em nível médio, no Estado do Paraná, é o trabalho como princípio educativo, concepção na qual está assentada uma visão educacional que concebe o trabalho como eixo do processo educativo.

No Paraná, a Proposta Pedagógica Curricular (PARANÁ, 2006, p. 19) do referido Curso sustenta que o trabalho, concebido como princípio educativo, "[...] deve ser o centro da formação humana em todo o ensino médio e não apenas naquele que tem o adjetivo de profissionalizante". Nesse sentido, adotar o trabalho como princípio educativo “[...] implica compreender a natureza da relação que os homens estabelecem com o meio natural e social, bem como as relações sociais em suas tessituras institucionais, as quais desenham o que chamamos de sociedade". 
Mas o que é o trabalho? Para se entender a concepção de trabalho como princípio educativo, tem-se que, primeiramente, apresentar uma definição de trabalho.

Sob uma perspectiva materialista histórica, o trabalho é uma atividade vital dos seres humanos. Desde que se concluiu o longo processo de evolução biológica da espécie humana, possibilitando um salto da história da natureza orgânica para a história social (DUARTE, 2003), deu-se início à constituição do homem como ser social. Concluído esse longo processo evolutivo, os membros da espécie humana adquiriram condições suficientes para passarem à história social, isto é, passaram à vida em uma sociedade organizada na base do trabalho.

O trabalho, conforme afirma Marx (1983, p. 149), "antes de tudo, [...] é um processo entre o homem e a Natureza, um processo em que o homem, por sua própria ação, media [sic], regula e controla seu metabolismo com a Natureza". Pelo trabalho, o ser humano coloca em ação as forças das quais é dotado o seu corpo, isto é, "[...] põe em movimento as forças naturais pertencentes à sua corporalidade, braços e pernas, cabeça e mão, a fim de apropriar-se da matéria natural numa forma útil para sua própria vida". $\mathrm{O}$ trabalho desenvolvido pelo ser humano promove as potências adormecidas da natureza "[...] e sujeita o jogo de suas forças a seu próprio domínio" (MARX, 1983, p. 149), à sua vontade.

Com base em Marx, Markus (1974, p. 48) destaca que o homem, pelo trabalho, é capaz de elevar-se acima dos limites que a natureza lhe impõe, de "[...] subordinar ao seu poder o conjunto da natureza, transformando tal conjunto em seu "corpo inorgânico"”.

Ao agir sobre a natureza externa, ideando previamente e pondo finalidade à sua ação, o ser humano modifica-a e, concomitantemente, modifica-se em âmbito subjetivo. De acordo com Duarte (1993, p. 31), o ser humano, nesse momento, “[...] ao produzir os meios para satisfação de suas necessidades básicas de existência, ao produzir uma realidade humana pela sua atividade, humaniza a si próprio, na medida em que a transformação objetiva requer dele uma transformação subjetiva".

Portanto, pelo trabalho, o ser humano cria, objetiva e subjetivamente, uma realidade humanizada, já que nela encarna sua capacidade de trabalho. Ao mesmo tempo em que o homem humaniza-se subjetivamente no processo de trabalho, que é sempre social, vai sendo educado na própria atividade desenvolvida. Nesse sentido, pode-se falar em princípio educativo pelo trabalho.

Sob esta perspectiva, é possível assinalar que o trabalho, tomado em seus elementos simples e abstratos, possui uma dimensão de criação da vida humana. Conforme afirmado por Marx (1983, p. 153) a esse respeito, o processo de trabalho

[...] é atividade orientada a um fim para produzir valores de uso, apropriação do natural para satisfazer as necessidades humanas, condição universal do metabolismo entre o homem e a Natureza, condição natural eterna da vida humana e, portanto, independente de qualquer forma dessa vida, sendo antes igualmente comum a todas as suas formas sociais.

Há um aspecto fundamental que se deve considerar quando se propõe entender o que é o trabalho à luz do materialismo histórico, indicado na última linha da citação apresentada. Trata-se da dimensão histórica do trabalho, isto é, de seu enraizamento nas diferentes formas sociais já criadas para a produção da vida humana.

Neste trabalho, interessa a forma social do capitalismo. No capitalismo, o produto do trabalho realizado pelo trabalhador não lhe pertence, uma vez que produz mercadorias que são de propriedade particular de outro, isto é, do capitalista. Por isso mesmo, o trabalho humano, na forma social do capitalismo, traz em si as marcas da alienação. Tais 
marcas também se fazem presentes na preparação, via educação escolar, para a execução do trabalho na sociedade capitalista. Por essa razão é que se questiona, aqui, acerca das reais possibilidades de se implementar, com êxito, no interior deste tipo de sociedade, propostas educativas contrárias à sua lógica hegemônica.

Destaca-se que propostas que têm como base o trabalho como princípio educativo opõem-se à lógica de formação capitalista. E por quê? Por defenderem que é o trabalho socialmente útil que deve organizar o trabalho pedagógico.

A noção de trabalho, sob essa perspectiva, não é tomada como meio de dignificação ou de disciplinamento do homem, mas aquilo que funda a vida humana. $\mathrm{O}$ trabalho educativo concebido por tal viés busca o desenvolvimento do indivíduo para além dos limites impostos pela divisão social do trabalho. Na realidade, o trabalho como princípio educativo respalda-se no fato de que no processo de transmissão do conhecimento pelo ensino é possível a apreensão dos elementos e propriedades que materializam um dado fenômeno, permitindo a construção de generalizações e da descoberta das leis do seu desenvolvimento.

Ademais, a defesa desse princípio passa pela questão de que a realidade humana é a cristalização do trabalho, logo, a criança na escola tem que se apropriar dos processos históricos cristalizados na realidade, ainda que o trabalho na forma social do capitalismo constitua-se como alienação e humanização.

Cabe observar que tem sido amplamente divulgada no cenário educacional brasileiro a definição de trabalho educativo formulada por Saviani (2003, p. 13), na qual postula que "O trabalho educativo é o ato de produzir, direta e intencionalmente, em cada indivíduo singular, a humanidade que é produzida histórica e coletivamente pelo conjunto dos homens".

Por certo que tal definição remete a outra lógica, contrária e alternativa à lógica dominante. Todavia, não se deve perder de vista que o trabalho e a educação na forma social do capitalismo, ao expressar interesses privados de acumulação de riquezas, não tem como objetivo precípuo a humanização. Pelo contrário, o interesse primeiro e primordial é a acumulação por meio da exploração do homem pelo homem. Evidências a esse respeito podem ser encontradas na história da Educação profissional, conforme se apresenta a seguir.

\section{Notas sobre a Educação Profissional no Brasil}

Ao esboçar o percurso histórico da Educação Profissional, é possível vislumbrar uma história multifacetada, na qual sua gênese, no Brasil colonial, foi marcada pelo preconceito contra o trabalho manual. Assim, originou-se uma formação técnica destinada aos desvalidos, abandonados e marginalizados como forma de compensação e civilização da população carente.

Nesse período no Brasil, o modelo econômico extrativista centrou-se no trabalho escravo e, com isso, houve uma grande resistência por parte do Império em permitir que se implantassem estabelecimentos industriais. O aprendizado profissional no Brasil foi retomado com a vinda da família real em 1808, que, ao chegar à Colônia, necessitou fazer várias adaptações para transformar o país em uma corte.

Entretanto, as primeiras instituições de ensino criadas por D. João VI foram destinadas à formação de um quadro de bacharéis para atender os interesses imediatistas da elite portuguesa. Entre as medidas de criação de cursos, D. João VI proibiu o monopólio do exercício das atividades das corporações, por meio da adoção de uma política econômica orientada pelos princípios do liberalismo, permitindo que qualquer pessoa vendesse 
mercadorias pelas ruas, desde que tivesse realizado o pagamento dos impostos devidos. Essa política foi um "[...] golpe mortífero na organização corporativa do trabalho manufatureiro" (CUNHA, 2005, p. 55).

Com a forte campanha da Inglaterra para a abolição da escravatura, o país necessitava de mão de obra para suprir algumas ocupações, para isso estabeleceu o ensino compulsório de ofícios às crianças e jovens excluídos socialmente - os órfãos e pobres desvalidos. Essa medida evidenciou a formação profissional reservada, desde as suas origens, "[...] às classes menos favorecidas, aqueles que necessitavam se engajar de imediato na força de trabalho e que não tinham acesso à escolarização básica regular" (CORDÃO, 2005, p. 44).

Após a proclamação da Independência do Brasil, a Constituição outorgada contemplou uma legislação especial sobre a instrução pública, porém, no ensino de ofícios, preservou a mentalidade conservadora construída ao longo do período colonial; ou seja, continuou a separação entre as ocupações para os pobres e desvalidos e a instrução para a elite.

A utilização de força de trabalho assalariado foi gerada vagarosamente a partir do ingresso de crianças, jovens órfãos e delinquentes e da imigração de mestres operários europeus para suprir a ausência do trabalho dos escravos. A mão de obra escrava entrou em processo de declínio diante das pressões da Inglaterra para o fim do tráfico.

Após a Proclamação da República, com o avanço das relações capitalistas e a influência da ideologia liberal, as preocupações educacionais se intensificaram e tornaramse mais fortes os apelos em torno da reforma e da difusão do ensino. Mas a forma de organização do novo regime, consolidado na "Política dos Governadores", no "voto de cabresto", nas fraudes eleitorais e no federalismo, o qual garantia o domínio das oligarquias regionais, em nada favoreceu a ampliação das oportunidades educacionais ou mudanças qualitativas da educação. A pressão social pela difusão do ensino foi absorvida pela elite defensora da "redenção" pela escola, que se incumbia de respaldá-la no ideário adequado e de pressionar o Estado.

\footnotetext{
Essa mobilização em torno de reivindicações educacionais era oportuna num período em que a crise da atividade agro-exportadora e o ensaio dos primeiros passos rumo a uma rearticulação econômica mais profunda ameaçavam a privatização do poder e, por essa via, a própria concentração de riqueza. Do ponto de vista das classes dominantes, cumpria, como sempre o fizera no passado e o faria freqüentemente no futuro, a função de canalizar as insatisfações sociais face um estado crônico de carência e exploração, sempre incompreendido e nunca resolvido (XAVIER, 1990, p. 63).
}

Nesse contexto, o sucesso e a incorporação dos pressupostos educacionais liberais decorreram da ignorância sobre as verdadeiras causas da miséria das camadas subalternas; do discurso das camadas médias, sequiosas de participação nos privilégios e manutenção da estrutura que as sustentava; e da retórica da elite dirigente, que alimentava essas ilusões.

O início do período republicano foi marcado por várias reformas, na tentativa de elaborar de uma nova política educacional para o país. Dentre os projetos, distinguiram-se os liberais, que expressavam o anseio de um país solidificado em bases urbano-industriais democráticas e defendiam uma educação regida pelas ideias da Pedagogia Nova. A Escola Nova opunha-se à escola tradicional ao procurar substituir a rigidez dos velhos programas, da memorização e dos exames desnecessários e priorizar a colaboração e a solidariedade entre os alunos. Assim como acontecera nos primeiros tempos da manufatura, em que o 
patrão agrupava os seus operários no mesmo local para economizar espaço, luz, etc., na escola, o trabalho era realizado isoladamente. Os técnicos da nova didática apropriavam-se dessa sugestão para reunir os alunos ao redor de "centro de interesses", associando-os mediante trabalhos em comum.

Ante a industrialização crescente e a deterioração das formas de produção no campo, ocorreram mudanças na economia nacional, a qual passou de um modelo agrário exportador para um modelo urbano-industrial, em que se impôs a necessidade de formação de mão de obra para os setores secundários e terciários da economia.

Com a instituição do sistema federativo de governo, a União reservou-se o direito de criar instituições de ensino superior e secundário nos Estados e prover a instrução secundária no Distrito Federal. Consequentemente, coube aos Estados manter e organizar a instrução primária e o ensino profissional, que compreendia as escolas normais para as moças e as escolas técnicas para os rapazes.

Essa determinação consagrou o dualismo na educação brasileira e oficializou a separação entre a educação para a classe dominante e a educação para o povo. Entretanto a estrutura social, para a qual se destinava à instrução pública primária e profissionalizante, apresentava-se mais complexa do que a anterior, na sociedade escravocrata. A composição social popular abrangia uma divergência de interesses, origens e posições. Existia uma pequena burguesia, uma camada média de intelectuais, a classe militar, uma burguesia industrial em ascensão e um contingente de imigrantes que, na zona urbana, ocupava-se de diferentes profissões e, na zona rural, dedicava-se à agricultura.

Quanto à Educação Profissional, permaneceu a ideia de que se destinava a regeneração e formação da população desfavorecidas social e economicamente, que se dava por meio de instituições confessionais e particulares.

O projeto de industrialização no Brasil consolidou-se no período do Estado Novo regime político comandado por Getúlio Vargas que vigorou de 1937 a 1945 - e as propostas para a educação objetivavam atender às demandas deste processo e do crescimento ascensional da população urbana (SANTOS, 2010). Desta forma, atendendo às demandas da sociedade, a Educação Profissional foi contemplada por meio das Reformas Capanema a partir de 1942, que resultaram na criação do Serviço Nacional de Aprendizagem Industrial (SENAI), bem como na reordenação do ensino industrial, secundário e comercial por meio de leis orgânicas.

Tais reformas estruturaram a educação brasileira em dois níveis: a educação básica e a superior; fez o ajuste entre as propostas pedagógicas existentes para a formação de intelectuais e trabalhadores, procurando adequá-las às mudanças que ocorriam no mundo do trabalho.

As reformas propostas para a Educação Profissional caracterizaram-se pela formação técnica, na qual a educação estava subordinada ao avanço das relações de produção vigentes na sociedade. No entanto, estava "[...] admitido o extremo atraso do país no campo econômico e conseqüentemente na área tecnológica ou dos meios de produção" (XAVIER, 1990, p. 101).

Em linhas gerais, o período do Estado Novo foi caracterizado pela ditadura e autoritarismo e o Estado fortaleceu-se no sentido de melhor servir aos interesses do capitalismo na sua política de controle das classes subalternas. A educação configurou-se pela tecnocracia e, concomitantemente, pela falta de unidade nacional, não se caracterizando por uma política educacional abrangente e democrática. Porém as Leis Orgânicas do Ensino cumpriram, de certa forma, com a função norteadora da educação, garantindo o controle da administração das escolas do ensino primário, ginasial e secundário. Quanto ao Ensino Normal, teve como finalidade a formação do pessoal 
docente necessário às escolas primárias, bem como a habilitação de administradores escolares para exercerem a função nessas escolas.

As reformas empreendidas (Reforma Francisco Campos e Reforma Capanema) oficializaram o dualismo educacional brasileiro, que reproduzia - através da estrutura do sistema educacional - a discriminação e os privilégios da estrutura econômico-social, mantidos e garantidos tanto no regime político "democrático" como no "autoritário". Assim, a "[...] política educacional nacional definia-se, cada vez mais nitidamente, como instrumento de cimentação da ordem econômico-social vigente" (XAVIER, 1990, p. 119).

Essa política referente ao ensino brasileiro se manteve até a Constituição de 1946, a qual determinou as diretrizes educacionais que se refletiram na primeira Lei de Diretrizes e Bases da Educação Nacional, aprovada em 1961. Durante o período de tramitação da Constituição, de 1946 até a LDB 4024/61, o país assistiu a uma crescente urbanização, forjada a partir da década de 1930, o que ocasionou aumento da classe proletária.

Em 1947, foi instalada uma comissão de educadores incumbidos de elaborar um projeto para a LDBEN. A discussão do projeto provocou debates de diferentes correntes educacionais, com diferentes interesses pela educação no período que antecedeu a aprovação da LDB. Esse período de lutas e divergências envolveu estudantes, operários, intelectuais, assim como forças conservadoras que temiam a democratização da vida nacional e o acesso das camadas populares à vida econômica.

A Lei 4.024, de 20 de dezembro de 1961, foi a primeira que definiu a finalidade da educação. Manteve a estrutura educacional organizada da seguinte forma: ensino préprimário, escolas maternais e jardins de infância; ensino primário com duração de quatro anos, podendo ser acrescidos mais dois anos para programas de artes aplicadas; o ensino médio foi subdivido em dois ciclos (ginasial de quatro anos e colegial de três anos), ambos compreendendo o ensino secundário e o ensino técnico (industrial, agrícola, comercial e de formação de professores); e ensino superior.

Os debates em torno da aprovação da Lei de Diretrizes e Bases de 1961

[...] se deram exatamente no período de redefinição dos rumos e da consolidação final da ordem capitalista lograda no país. Consubstanciou, com clareza inquestionável, a insatisfação das classes dominantes, tanto dos grupos tradicionais como do novo empresariado, diante dos impasses gerados pelo padrão de acumulação, nacionalista e protecionista, intentado pelo governo autoritário (XAVIER, 1990, p. 169).

Conforme o contexto da época, o atendimento educacional à população foi se transformando e se adaptando para atender às exigências do capital. Com o discurso de civilizar a sociedade, a classe dominante impôs sua ideologia e a utilizava como um dos recursos à educação da população. Com isso, criou-se a elitização do ensino, um voltado para formar a classe dirigente do país e outro para formar mão de obra preparada para atuar nas indústrias e também no campo.

Observa-se que o dualismo estrutural existente entre ensino médio propedêutico e educação profissional de nível médio tem, desde a sua origem, demandado desafios para transformação da educação em uma escola unitária. E, ainda que os problemas apontados na estrutura da Educação Profissional são de ordem política e não pedagógica, uma vez que

[...] a dualidade estrutural tem suas raízes na forma de organização da sociedade, que expressa as relações entre capital e trabalho; pretender 
resolvê-la na escola, através de uma nova concepção, ou é ingenuidade ou é má fé" (KUENZER, 2007, p. 34).

Nesse sentido, não bastaria promover reformas na educação brasileira, visto que as mudanças introduzidas sob o padrão capitalista de acumulação é geradora de tensões e contradições entre o sistema educacional e as novas necessidades de educação para o trabalho. Essas necessidades fazem emergir, por exemplo, a partir dos anos de 1990, os debates acerca da reestruturação do ensino médio e profissional para atender aos processos de "[...] reestruturação produtiva de internacionalização da economia brasileira e de pressão pela ampliação de direitos sociais" (MANFREDI, 2003, p. 108).

Mediante esse retrospecto acerca do itinerário da Educação Professional no Brasil, é possível observar que a preparação, via escola, para a execução do trabalho na sua forma capitalista não está de modo algum isenta da lógica do capital. Com o intuito de afunilar tal discussão, a partir de um dos cursos de Educação Profissional, apresenta-se a seguir o percurso histórico do curso, em nível Médio, de formação para o magistério.

\section{Notas sobre a formação de professores no Brasil: antecedentes históricos e reconfigurações}

A formação de professores em nível médio constitui-se em um dos cursos de Educação Profissional. Embora oferecido nos dias atuais, sua origem não é recente, na realidade remonta o século XIX.

Com o fito de traçar um panorama histórico desse curso, é apresentada uma caracterização do itinerário da Escola Normal no Brasil, adotando-se como fio condutor as reformas e leis que foram implementadas no país. Busca-se, para isso, evidenciar o contexto econômico, político e social que influenciou na organização desse grau de ensino, o qual por aproximadamente um século constituiu-se no único curso de formação de professores.

Para iniciar a caracterização proposta, é possível destacar dois marcos importantes relacionados ao período imperial: a fase jesuítica e a vinda da família real portuguesa para o Brasil. No primeiro, a educação ficou a cargo dos religiosos, com a intenção de instruir e catequizar os índios e, mais tarde, os filhos dos gentios e cristãos. Já o segundo marco, caracterizado pela instalação da família real e tentativa de transformar a colônia em sede da corte, medidas foram tomadas para atender as necessidades da população, de modo que alterações na área educacional foram efetuadas, tais como a criação de cursos superiores e bibliotecas.

Tais medidas, entretanto, causaram poucas modificações na situação do ensino primário e secundário, uma vez que a preocupação era exclusivamente com os cursos superiores. Esses deveriam atender as necessidades do mercado de trabalho e, para seu desenvolvimento, necessitariam de profissionais qualificados. Nas escolas secundárias, que davam acesso a esses cursos, frequentados pela minoria latifundiária ou da elite da Corte, a educação manteve uma tradição aristocrática, que vinha desde os tempos dos jesuítas.

Nesse período, teve início uma formação assistemática de professores como uma tentativa para organizar um sistema de instrução primária. Essa iniciativa para a formação de professores estava baseada na observação e na imitação de modelos, centrada na aprendizagem do Método Mútuo e marcou a formação antes e depois da criação da Escola Normal. A adoção do método mútuo estava em consonância com o espírito da época, "[...] com o qual esperava acelerar a difusão do ensino atingindo rapidamente e a baixo custo grande número de alunos" (SAVIANI, 2012, p. 128). 
Ocorreu, ainda, uma iniciativa de organização e normatização do exercício da profissão docente, mas foi com a criação da Escola Normal que teve início uma nova etapa nesse processo.

Com o Ato Adicional de 1834, as províncias adquiriram poderes legislativos, garantindo a elaboração do seu próprio regimento, desde que estivesse em consonância com as imposições do Estado. Foi nesse clima de organização da administração da província do Rio de Janeiro, que o presidente da província do Rio de Janeiro propôs a criação da Escola Normal. A preocupação com a formação docente respondia aos interesses dos dirigentes fluminenses, cujo intuito era tornar o professor um agente do Estado, capaz de formar futuros homens e cidadãos civilizados e assim romper as "trevas" que caracterizavam o passado colonial. Foi a partir dessa necessidade de instruir o povo e centralizar o poder da classe dirigente que surgiu a Escola Normal do Rio de Janeiro. Tal escola destinava-se aos pretendentes à carreira docente e aos professores que exerciam o magistério.

Foi, portanto, no contexto histórico do século XIX, que surgiram as primeiras Escolas Normais e teve início a formação de professores para o ensino primário. Fundou-se em Niterói a primeira Escola Normal em 1835, na Bahia em 1842, em São Paulo no ano de 1847, no Rio Grande do Sul em 1869 e no Paraná no ano de 1876.

Nos estudos de Kulesza (1998, p. 66), sobre a institucionalização da Escola Normal no Brasil, salienta-se que, ao analisar o "[...] conteúdo da cadeira de Pedagogia assim criada e a pouca ênfase dada à prática pedagógica, pode-se concluir que esse curso tinha por objetivo a formação de dirigentes para o ensino público". Esse objetivo distanciava as mulheres do magistério, ficando o curso reservado essencialmente aos homens.

Em São Paulo, a Escola Normal funcionou, inicialmente, com uma seção masculina anexa à Faculdade de Direito e uma seção feminina anexa ao Seminário da Glória, a qual "[...] parece ter surgido como meio de encaminhar as internas do Seminário, mantidas por donativos públicos e particulares" (CAMPOS, 1990, p. 7). De acordo com os padrões morais da época, a moça que atingisse 18 anos e não fosse pedida em casamento ou empregada como doméstica nas casas de famílias de "bons costumes" deveria preencher as cadeiras vagas na seção feminina. Portanto, a função docente era considerada como um prolongamento da vida do lar.

Com todas essas dificuldades, além do pouco interesse pela carreira docente e evasão dos alunos, a Escola Normal de Niterói foi extinta em 1851. A extinção das escolas justificava-se pelo argumento de serem muito onerosas, ineficientes quanto à qualidade da formação que ministravam e insignificante em relação ao número de alunos que se formavam (SAVIANI, 2010). Para substituir as escolas, o governo contratou professores auxiliares, por meio de concurso, para auxiliarem e se aperfeiçoarem nas matérias e práticas do ensino. Desta forma, "[...] pela via da atuação como auxilia junto a um professor público em exercício, se buscou formar os novos professores, dispensando-se a instalação de Escolas Normais" (SAVIANI, 2010, p. 133).

A criação das primeiras Escolas Normais não previa a presença de alunas; mais tarde, após a recriação das escolas extintas foram feitas várias tentativas para colocar moças e rapazes em dias alternados ou em prédios separados.

A partir da segunda metade do século XIX, o magistério começou a configurar-se como profissão feminina por excelência. Os homens, considerados como "chefes de família", buscavam outras profissões mais rentáveis e aqueles que permaneciam exercendo o magistério recebiam tratamento diferenciado em relação à carreira e à remuneração. $\mathrm{O}$ salário pouco compensador foi um fator que acarretou o afastamento dos homens da carreira docente. 
A profissionalização feminina no magistério público partiu do entendimento de que a educação escolar era uma extensão da educação dada em casa. Portanto, a função de mãe na família era estendida à escola pela pessoa da professora; com isso, criava-se o círculo que permitiria a profissionalização do magistério feminino.

Nesse processo, o magistério consolidou-se não apenas numericamente como profissão feminina, mas também como forma respeitável e institucionalizada de emprego para as mulheres de classe média. A predominância feminina aliou-se, no entanto, ao conceito de vocação, já que a mulher foi considerada naturalmente apta para o exercício do magistério.

A Escola Normal ampliou-se gradativamente no século XX. A ruptura com o regime monárquico e a implantação da República, a vinda de imigrantes e a ascensão da burguesia industrial foram algumas transformações no cenário nacional que influenciaram a estrutura educacional.

A primeira Constituição Republicana, no artigo 34, alínea 30, definiu que a União ficaria responsável em legislar sobre a organização municipal do Distrito Federal e o ensino superior, enquanto que a Escola Primária e a Escola Normal continuavam sob a alçada dos estados.

Apesar das reformulações sucessivas no ensino normal, evidenciou-se a ausência de uma linha de continuidade e coerência entre as diversas propostas. No início do século XX, a política educacional brasileira ocupava-se mais especificamente com o ensino superior do que com os outros graus de ensino. Portanto, continuava presente a diferenciação da educação destinada às elites, nos ginásios que encaminhavam para o curso superior, e a educação destinada ao restante da população, em Escolas Complementares e Escolas Normais, que possibilitavam o exercício de uma atividade. Destaca-se que a ampliação da Escola Normal conformou-se com os projetos das oligarquias regionais, que buscava alfabetizar a população analfabeta e assim aumentar o contingente de eleitores.

A responsabilidade atribuída à Escola Primária estimulou uma ampla discussão em torno da Escola Normal, pois essa deveria oportunizar condições para que o professor executasse a sua missão.

Em um cenário que passou a contar com a industrialização crescente, deterioração das formas de produção no campo, bem como a mudança de um modelo agrário exportador para um modelo urbano-industrial, tornou-se necessário a formação de mão-de-obra para os setores secundários e terciários da economia. Diante disso, coube aos Estados a manutenção e organização da instrução primária e do ensino profissional. Este último compreendia as escolas normais - para as moças - e as escolas técnicas - para os rapazes.

Justamente para atender as demandas existentes que uma educação de cunho mais profissionalizante foi contemplada pela Reforma Capanema a partir de 1942, levada a cabo por meio das chamadas Leis Orgânicas, isto é, seis decretos-lei que passaram a ordenar o ensino primário, secundário, industrial, comercial, normal e agrícola. Referente ao ensino normal, salienta-se que segundo o Decreto-lei n. ${ }^{\circ} 8530$, de 2 de janeiro de 1946, o mesmo tinha como finalidade formar professores para as escolas primárias, habilitar administradores escolares, bem como desenvolver e propagar conhecimentos e técnicas sobre a educação da infância.

O curso estava dividido em dois níveis, sendo o primeiro destinado à formação de regentes de ensino primário, com duração de quatro anos, funcionando em escolas denominadas de Escolas Normais Regionais; e o segundo voltado para a formação de professores primários, com duração de três anos, que funcionaria em Escolas Normais. Além das Escolas Normais Regionais e Escolas Normais, também foram criados os Institutos de Educação, que funcionavam com Jardim de Infância e Escola Primária 
anexos, com cursos de especialização de professor primário e habilitação de administradores escolares. As alunas que ingressavam nos Institutos de Educação, posteriormente poderiam cursar a Faculdade de Filosofia, sendo esse percurso destinado às camadas populares; já os filhos da elite poderiam cursar o primário, depois o ginásio, o colégio e, finalmente, optar por qualquer curso superior.

Posteriormente, na década de 1960, promulgou-se a primeira Lei de Diretrizes e Bases da Educação Nacional, n. ${ }^{\circ}$ 4024/61, a qual não trouxe alterações significativas para o Ensino Normal. Segundo a lei, a formação do professor primário dar-se-ia em Escolas Normais de primeiro e segundo ciclos, como a Lei Orgânica do Ensino Normal já havia proposto anteriormente. E, para os professores leigos, continuariam os exames de suficiência, os quais davam direito ao registro de professor.

O período que se estende da promulgação da primeira LDB e a implantação da Lei 5692/71 é marcado pelo intenso avanço industrial brasileiro, decorrente da economia mundial e do desenvolvimento tecnológico, repercutindo em toda a esfera nacional. Com a aceleração industrial, exigiu-se mão-de-obra qualificada em um período pequeno, para atender à demanda profissional. Surgiu, pois, a organização do ensino com base no modelo tecnicista, presente nesse período. Essa tendência resultou na tentativa de aplicar na escola o modelo de racionalização adotado pelas empresas, próprio do sistema capitalista. Portanto, tentou-se adequar as bases de tal modelo na área educacional, para atender as exigências da industrialização, com economia de esforços e tempo.

A partir da lei de reforma da educação nacional de $\mathrm{n}^{\circ} .5 .692$ de 1971, a qual fixou as diretrizes e bases do ensino de $1^{\circ}$ e $2^{\circ}$ graus, houve modificações à profissionalização nos cursos de $2^{\circ}$ grau. No caso da formação dos professores para o ensino primário, ela deveria ocorrer, segundo a lei, por meio da habilitação específica para o magistério em nível de $2^{\circ}$ grau. Nesse momento, as denominações Escola Normal e Institutos de Educação desaparecem e passa a ser usada a expressão Habilitação ao Magistério (TANURI, 2000).

Tal denominação vigorou até a segunda metade dos anos de 1990, visto que em atendimento à LDB nº 9.394/96, novas mudanças entraram em vigor no cenário nacional. Uma das mudanças foi o fechamento, em alguns Estados da Federação, dentre eles o Estado do Paraná, do curso de formação de professores em nível Médio oferecido na rede pública.

Para efeito de recorte espacial, atentar-se-á, doravante, ao caso paranaense. A razão para tal escolha assenta-se na especificidade do movimento vivido no Estado, isto é, de extinção do curso concomitante a uma resistência a tal medida e, posteriormente, de reabertura do mesmo, o qual contou com a publicação de uma Proposta Pedagógica que adota como um de seus pilares o trabalho como princípio educativo, uma referência crítica em educação conforme explicitado anteriormente.

\section{Notas sobre a formação de professores no Paraná: contextualização da Proposta Pedagógica Curricular do curso de Formação de Docentes na modalidade Normal}

No Paraná a segunda década dos anos de 1990 foi marcada por uma mudança drástica no curso de formação de professores com a extinção do curso de Magistério. No Estado, o curso de formação de professores em nível Médio, assim como outros cursos de educação profissional, foi extinto no ano de 1996 por ordenação da Secretaria de Educação do Estado do Paraná (SEED-PR), que ao mesmo tempo propôs uma reestruturação do Ensino Médio (que deixaria de ser profissionalizante) por meio do Programa de Melhoria e Expansão do Ensino Médio (PROEM). Tal Programa, segundo Piassa (2007), recebeu 
financiamento externo de uma das agências do Banco Mundial, isto é, do Banco Interamericano de Desenvolvimento.

Ainda que manifestações contrárias às determinações do PROEM tenham acontecido, conforme evidenciam Miranda (2000) e Sapelli (2003), houve pressão por parte do governo do Estado, à época, para que as escolas paranaenses aderissem ao mesmo. Por meio de instrumento legal, foi determinado que as escolas não mais poderiam efetuar matrículas no curso de Magistério, já que estas seriam bloqueadas.

O problema maior é que não houve a expansão do Ensino Médio tampouco a criação de uma nova rede de cursos profissionalizantes conforme se justificava diante do fechamento dos cursos profissionalizantes da rede estadual. $\mathrm{O}$ que foi criado, na realidade, foi uma empresa sem fins lucrativos, denominada PARANATEC - Agência para o desenvolvimento da Educação Profissional do Paraná, que significou, segundo análise de Miranda (2000), o primeiro passo rumo ao processo de privatização da rede de ensino profissionalizante. Com isso, tornou-se possível a expansão dos cursos profissionalizantes pagos. O apoio do governo voltou-se, então, para apoiar a formação em nível pós-médio.

Os cursos profissionalizantes, entre eles o de Magistério, foram desativados em quase todo o Estado do Paraná. Entretanto, 14 escolas não aceitaram as decisões do governo e mantiveram o referido curso em funcionamento, mesmo sob forte e persuasivo discurso em prol da reforma que estava em andamento.

Tal cenário começou a mudar a partir do ano de 2003, momento em que é iniciada uma discussão para a retomada dos cursos na rede pública estadual. O Departamento de Educação Profissional do Estado do Paraná assume, a partir de então, a responsabilidade do setor público na oferta do curso de formação de professores em nível Médio. A justificativa para tal retomada foi a de que havia um grave problema de falta de professores para a Educação Infantil em todo o Estado (PARANÁ, 2006).

Desde a sua reabertura nas escolas públicas paranaenses, o curso de formação de professores em nível Médio, não mais denominado de Magistério e sim de Curso de Formação de Docentes, teve grande procura. Evidência disso foi a rápida retomada do curso. Se em 2003 a formação de professores era oferecida em 14 escolas, no ano seguinte o número era de 45 e em 2005 de 70 escolas.

Em relação à Proposta Pedagógica Curricular do curso de Formação de Docentes para a Educação Infantil e Anos Inicias do Ensino Fundamental, em nível Médio, na modalidade Normal, destaca-se que os trabalhos para sua elaboração foram iniciados no ano de 2003. No processo de sua elaboração, tal documento contou com a participação de professores da rede pública estadual, Núcleos Regionais de Educação, Departamento de Educação Profissional da Secretaria de Estado da Educação, além de docentes das Instituições de Ensino Superior do Paraná.

Com o propósito de ser um material permanente de discussão e reelaboração acerca da política de formação de professores na rede pública estadual paranaense, tal Proposta, publicada em 2006, trouxe uma concepção alternativa para a formação de professores ao fundamentar-se no trabalho como princípio educativo como base para a constituição do trabalho docente. Seus objetivos podem ser assim sintetizados: formar profissionais que sejam capazes de desenvolver um trabalho coletivo e colaborativo; investigar problemas e buscar soluções; realizar práticas educativas capazes de desenvolver nos educandos a cidadania e a criticidade; realizar um trabalho em conformidade com o estabelecido pelas Diretrizes Curriculares Nacionais para a Educação Básica; e, ainda, valer-se de linguagens tecnológicas (PARANÁ, 2006).

Ainda que seus objetivos sejam condizentes à concepção adotada, entende-se que alguns questionamentos cabem ser feitos acerca da viabilidade de se auferir esta 
capacitação profissional dentro das peculiaridades da sociedade atual. Nesse sentido, questiona-se:

- numa sociedade voltada para a produção desenfreada e a busca incessante pelo lucro, a formação dos profissionais não estaria alicerçada nas prerrogativas deste modelo de produção material da vida humana, isto é, constituir-se com baixos custos, sem morosidade e com a máxima eficiência possível?

- escaparia a formação de docentes da lógica do mercado, estabelecendo-se fundamentada em outros parâmetros?

- haveria espaço para a formação de professores críticos numa sociedade que impregna a todos com o imperativo da eficiência e dos resultados quantificáveis?

Ademais, é preciso considerar que a concepção tecnicista ainda é fundamento do pensar e do agir nos contextos escolares. Tal concepção certamente continua a vigorar porque atende às necessidades da sociedade capitalista de formação de um grande número de profissionais de modo barato e rápido, já que para acelerar o crescimento econômico são imprescindíveis profissionais capacitados para tal. É fato que a formação destes profissionais ocorre primeiramente no âmbito da Educação Básica - e na maioria das vezes restrita a essa etapa, o que exige um contingente significativo de professores. Portanto, aligeirar a formação de docentes está em consonância com as necessidades do mercado de trabalho da sociedade capitalista.

Se, por um lado, tal constatação reforça a validade de se questionar sobre a viabilidade de se formar professores críticos dentro deste contexto societário; por outro lado, não se pode perder de vista as possibilidades de se curvar a vara para o outro lado (SAVIANI, 2007), tarefa que no atual modelo de sociedade mostra-se cada vez mais complexa e exige um amplo trabalho coletivo, consciente e intencional. Embora a negação da viabilidade de uma formação alternativa, tal qual aventada pela Proposta Pedagógica do curso de Formação de Docentes no Estado do Paraná, seja uma realidade, sua afirmação quiçá seja possível na condição de conquista coletiva.

\section{Considerações finais}

A discussão ora apresentada versou sobre a relação entre trabalho, educação profissional e formação, em nível médio, de professores. Orientando-se por tal relação, foi possível observar que sempre em consonância com as demandas socioeconômicas criadas a partir das diferentes conjunturas do país a formação profissional, precisamente a formação para o magistério, uma das modalidades de Educação Profissional, já foi, entre outros papéis, símbolo de distinção social, formação permitida socialmente para moças que buscavam trabalho fora do lar, bem como preparação rápida e de baixo custo da força de trabalho para atender ao mercado.

Acerca de alguns elementos gerais que marcaram sua trajetória destaca-se que a existência do curso de formação de professores, em todas as suas fases, está intimamente relacionada às demandas materiais da sociedade brasileira. Se, em um primeiro momento, dispensava-se a educação formal, haja vista o trabalho ser manual e exigir poucas habilidades intelectivas, em um momento posterior, com o advento da industrialização e, concomitantemente, com o processo de urbanização, a escola tornou-se uma necessidade para educar o homem requisitado para uma nova configuração social capitalista. 
Por isso mesmo, a instrução primária entrou na ordem do dia e passou a ser propalada como responsável pelo progresso social, solução para os problemas relacionados à sociedade e a garantidora do futuro da civilização, trazendo benefícios de ordem econômica e política. Seu objetivo seria o de promover o progresso, a justiça, a moralidade e o trabalho. Ao tornar-se um empreendimento necessário para sociedade capitalista, a criação da escola primária passou a gerar a necessidade de se formar professores para atuar nas escolas criadas.

Como bem discute Miguel (1997), a criação dos cursos normais está relacionada à criação e à expansão das escolas primárias preparatórias da força de trabalho para ser explorada em uma sociedade que alavancava seu processo de industrialização e urbanização. Nesse sentido, requisitava-se que os professores formados pelos cursos normais dessem conta de ensinar rudimentos de leitura, escrita e cálculo, além de incutir novos hábitos de higiene, economia e moral. Isto porque um país em desenvolvimento industrial necessitava de trabalhadores minimamente alfabetizados e moralmente preparados para uma ordem geradora de progresso.

Pode-se observar que, consoante a um projeto de nacionalidade em andamento, o modelo de escola defendido era aquele equiparado ao de uma oficina ou empresa, cuja tônica era a primazia da eficiência técnica. Em atendimento a esse modelo de escola, era objetivo do Estado preparar professores capazes para ensinar e aptos a transmitir os valores urbanos de vida social para uma população que, até então, era eminentemente rural, habituada ao trabalho do campo e pouco consumista.

Ainda que essa função do curso de formação de professores tenha sido reconfigurada ao longo das décadas, sobretudo a partir do terceiro quartel do século passado, o mesmo sobrevive às vicissitudes e contradições que o atravessam, ora perdendo espaço, ora sendo fortalecido por políticas públicas como é, por exemplo, o caso do Estado do Paraná, que tem oferecido o curso em escolas da rede pública estadual.

A respeito da experiência do Paraná, foi possível constatar que ainda que a concepção teórica e metodológica da Proposta Pedagógica do referido Estado esteja calcada numa perspectiva crítica, ao defrontar suas proposições com a realidade estas não encontram terreno propício para fecundarem. Mesmo que tal Proposta Pedagógica Curricular aponte para uma perspectiva educacional com base no trabalho como princípio educativo, no cotidiano o que é possível ser efetivado é algo bem distinto. Isso certamente se deve à distância entre o proposto e o efetivado, que tem seus fundamentos pautados no terreno contraditório e antagônico das determinações do capital, cuja margem para a consecução de propostas educativas alternativas que lhe são concorrentes e, até mesmo, negadoras, é por demais estreitas, daí prevalecer uma preparação aligeirada para o mercado de trabalho, gerador das contradições sociais.

Entende-se que, diante do fato de o Curso de Formação de Docentes ser constituído por filhos da classe trabalhadora, trata-se de um espaço de luta a ser conquistado com vistas a uma formação que possa contribuir para o desvelamento das relações sociais de produção, isto é, para o desvelamento da exploração do homem pelo homem, combatendo argumentos que mascaram o real significado da educação profissional e dos esforços do Estado capitalista para promover um rápido acesso ao mercado de trabalho. Por esse prisma, urge a contraposição a uma formação cuja função se volte exclusivamente para as atuais demandas da sociedade capitalista, que visa impingir a obediência, disciplinando corações e mentes e, assim, preparando trabalhadores dóceis e resignados para um mercado voraz e para salários aviltantes.

Para finalizar, assinala-se que uma ampla discussão acerca dos desafios atuais para a formação em nível Médio de professores, impõe-se com urgência para todos os 
educadores comprometidos com outro modelo de sociedade. Ademais, assinala-se que mais do que atender às finalidades propostas para o Ensino Médio e Educação Profissional, qual seja, a formação de técnicos, considera-se primordial uma formação que possibilite aos alunos compreender a realidade em que estão inseridos e lhe atribuir sentido, participando ativamente de seu processo formativo.

\section{REFERÊNCIAS}

CAMPOS, M. C. S. S. Formação do magistério em São Paulo: do império a 1930. Cadernos de Pesquisa, São Paulo, n.72, p.5-16, fev. 1990.

CORDÃO, F. A. A educação profisssional no Brasil. In: PROGRAMA DE ESTUDOS PÓS-GRADUADOS EM EDUCAÇÃO - PUC/SÃO PAULO (Org.). Ensino Médio e ensino técnico no Brasil e em Portugal: raízes históricas e panorama atual. Campinas, SP; Autores Associados, 2005.

CUNHA, L. A. O ensino de ofícios nos primórdios da industrialização. São Paulo: Ed. UNESP; Brasília, DF: FLACSO, 2005.

DUARTE, N. A individualidade para-si: Contribuições a uma teoria histórico-social da formação do indivíduo. Campinas, SP: Autores Associados, 1993.

Sociedade do conhecimento ou sociedade das ilusões? Quatro ensaios críticodialéticos em filosofia da educação. Campinas, SP: Autores Associados, 2003.

KUENZER, A. (Org.). Ensino médio: Construindo uma proposta para os que vivem do trabalho. 5. ed. São Paulo: Cortez, 2007.

KULESZA, W. A. A institucionalização da Escola Normal no Brasil (1870-1910). Revista Brasileira de Estudos Pedagógicos, Brasília, v.79, n.79, p. 63-71, set./dez. 1998.

MANFREDI, S. M. Educação profissional no Brasil. São Paulo: Cortez, 2003.

MARKUS, G. A teoria do conhecimento no jovem Marx. Rio de Janeiro: Paz e Terra, 1974.

MARX, K. Trabalho alienado e superação positiva da auto-alienação humana. In: FERNANDES, F. (Org.). Marx e Engels: história. São Paulo: Ática, 1983. p. 146-181.

MIGUEL, M. E. B. A formação do professor e a organização social do trabalho. Curitiba: Ed. UFPR, 1997.

MIRANDA, M. F. de. Num quintal da globalização: reflexo do processo de ocidentalização do mundo na educação brasileira de ensino médio. 2000. 203 f. Tese (Doutorado em Educação)-Unesp, Marília, SP, 2000.

PARANÁ. Proposta pedagógica curricular do curso de formação de docentes para a Educação Infantil e Anos Iniciais do Ensino Fundamental. Curitiba: SEED, 2006.

PIASSA, Z. A. C. Como fênix renascida das cinzas: análise do processo histórico do curso de Formação de Docentes em nível Médio no Estado do Paraná. Anais... VII Jornada do Histedbr, Campo Grande, MS, 2007, p. 1-26.

SANTOS, J. A. dos. A trajetória da educação profissional. In: LOPES, E. M. T.; FARIA, L. M. F.;VEIGA, C. G. (Org.). 500 anos de educação no Brasil. 4. ed. Belo Horizonte: Autêntica, 2010. p. 205-224. 
SAPELLI, M. L. S. Políticas educacionais do Governo Lerner no Paraná (1995-2002). Cascavel: Igol, 2003.

SAVIANI, D. Escola e Democracia: curvatura da vara, onze teses sobre a educação política. 39. ed. Campinas, SP: Autores Associados, 2007.

Pedagogia histórico-crítica: primeiras aproximações. 8. ed. Campinas, SP: Autores Associados, 2003.

2010. . História das ideias pedagógicas no Brasil. Campinas/SP: Autores Associados,

TANURI, L. M. História da formação de professores. Revista Brasileira de Educação, São Paulo, n. 14, p. 61-88, maio/jun./jul./ago. 2000.

XAVIER, M. E. S. P. Capitalismo e escola no Brasil. Campinas, SP: Papirus, 1990.

Nota:

${ }^{1}$ Versão revisada do artigo apresentado no V Encontro Brasileiro de Educação e Marxismo, em Florianópolis-SC, em abril de 2011.

Recebido em fevereiro/2012

Aprovado em junho/2012 